\title{
CRESCIMENTO E PARTIÇÃO DE MATÉRIA SECA E DE CARBONO NO MAMOEIRO EM RESPOSTA À NUTRIÇÃO NITROGENADA ${ }^{(1)}$
}

\author{
JAILSON LOPES CRUZ(2); EUGÊNIO FERREIRA COELHO ${ }^{(2)}$; CLAUDINÉIA REGINA PELACANI ${ }^{(3)}$; \\ MAURÍCIO ANTÔNIO COELHO FILHO ${ }^{(4)}$; ANTONIVALDA TOSTA DIAS ${ }^{(5)}$; \\ MARTA TALUANA DOS SANTOS ${ }^{(5)}$
}

\begin{abstract}
RESUMO
Avaliou-se o efeito da nutrição nitrogenada sobre a produção e partição de matéria seca e sobre alteração na concentração de alguns carboidratos solúveis, em mamoeiro da variedade 'Sunrise solo'. O delineamento experimental foi em blocos casualizados com três tratamentos (níveis de $\mathrm{NO}_{3}^{-}$) e cinco repetições, sendo cada planta considerada uma parcela experimental. As plantas cresceram em diferentes soluções nutritivas, contendo três concentrações de $\mathrm{NO}_{3}^{-}\left(1,0 ; 3,0 ; 5,0 \mathrm{~mol} \mathrm{~m}^{-3}\right)$. Sessenta e quatro dias após a semeadura verificou-se que a produção de massa seca total, do caule, da folha e das raízes, bem como os valores da área foliar, razão de área foliar (RAF), razão de massa foliar (RMF), razão de massa do caule (RMC) e área foliar específica (AFE) foram menores para as plantas crescidas sob menor disponibilidade de nitrogênio. No entanto, a relação raiz:parte aérea não apresentou diferenças entre os tratamentos, indicando não ter havido ajustamento na distribuição de carbono entre essas partes da planta. A concentração dos açúcares solúveis totais (AST), açúcares redutores (AR) e açúcares não-redutores (ANR) aumentou com o incremento dos níveis de $\mathrm{NO}_{3}^{-}$na solução. Já a concentração de amido foi maior para as plantas crescidas sob deficiência de $\mathrm{NO}_{3}^{-}$, bem como para a relação amido/ANR, sugerindo ter havido redução nos níveis de exportação dos assimilados produzidos.
\end{abstract}

Palavras-chave: Carica papaya L., nitrato, raiz:parte aérea, açúcares, amido.

\section{ABSTRACT \\ GROWTH AND DRY MATTER AND CARBON PARTITION IN PAPAYA PLANTS IN RESPONSE TO NITROGEN NUTRITION}

The objective of this work was to evaluate the effect of nitrogen nutrition on production and partition of dry matter and the change of some leaf sugars concentrations in 'Sunrise solo' papaya plants. The work was carried out in a randomized blocks experimental design with three treatments (levels of $\mathrm{NO}_{3}^{-}$) and five replications, where each plant was considered an experimental unit. Plants were fertilized with different nutritional solutions prepared to present three concentrations of $\mathrm{NO}_{3}^{-}\left(1.0 ; 3.0 ; 5.0 \mathrm{~mol} \mathrm{~m}^{-3}\right)$. The experiment ended sixty-four days after sowing. It was shown that total dry matter production of stem, leaf and roots, as well as the values of leaf area, leaf area/leaf mass ratio, stem mass and specific leaf area were smaller for plants grown under lower nitrogen availability. However, the root/shoot ratio did not show differences among treatments, indicating that there was no adjustment in carbon partition between these plant parts. The concentrations of total soluble sugars (TSS), reducing sugars (RS) and not reducing sugars (NRS) increased with the increase of $\mathrm{NO}_{3}^{-}$in solution. An opposing trend was noted for starch concentration, higher for plants grown under $\mathrm{NO}_{3}^{-}$deficiency. The starch/NRS ratio was higher for plants grown under lower $\mathrm{NO}_{3}^{-}$availability, suggesting that there was a reduction of export levels of assimilates produced.

Key words: Carica papaya L., nitrate, root/shoot ratio, sugars, starch.

$\left.{ }^{1}\right)$ Recebido para publicação em 11 de novembro de 2003 e aceito em 23 de junho de 2004.

$\left(^{2}\right)$ Embrapa Mandioca e Fruticultura, Caixa Postal 007, 44380-000 Cruz das Almas (BA). E-mail: jailson@cnpmf.embrapa.br

$\left({ }^{3}\right)$ Universidade Estadual de Feira de Santana, Rod. BR-116, 44031-460 Feira de Santana (BA). E-mail: pelacani@uefs.br

$\left({ }^{4}\right)$ Bolsista CNPq, vinculado à Embrapa Mandioca e Fruticultura.

$\left({ }^{5}\right)$ Escola de Agronomia da UFBA, 44380-000 Cruz das Almas (BA). Bolsista FAPESB. 


\section{INTRODUÇÃO}

No Brasil, a cultura do mamoeiro tem grande importância econômica, visto que o País apresentase como o maior produtor mundial da fruta (FAO, 2002). Entretanto, a cultura é exigente em insumos agrícolas, sendo necessário desenvolver tecnologias que permitam reduzir o custo de produção e, ou possibilitem incorporar áreas marginais no processo produtivo dessa cultura, como por exemplo solos de baixa fertilidade. Nesse aspecto, a avaliação do efeito da deficiência de nitrogênio sobre alguns aspectos da fisiologia dessas plantas pode contribuir para identificar variedades mais eficazes no uso desse nutriente, reduzindo-se, como conseqüência, a necessidade de altas aplicações de fertilizantes nitrogenados.

O nitrogênio tem efeitos sobre a assimilação de carbono, produção de biomassa e rendimento econômico das culturas (Evans, 1989). Plantas crescidas com quantidade inadequada de nitrogênio não expressam totalmente seu potencial genético, pois, sob tais condições, ocorre uma série de alterações morfológicas e fisiológicas, afetando, negativamente, o crescimento das plantas (Evans, 1989). Esse problema tem levado à afirmação de que o nitrogênio é um dos nutrientes que mais tem limitado o aumento de rendimentos das culturas (GREENWOOD et al., 1991), especialmente nos trópicos. A deficiência de nitrogênio, além de reduzir o crescimento, pode afetar a partição de assimilados entre as diferentes partes da planta, ocasionando, geralmente, aumento na relação entre a massa seca das raízes e a massa seca da parte aérea (CRUZ, 2001).

A deficiência de nitrogênio pode influenciar a alocação do carbono assimilado, alterando a proporção do amido, sacarose e monossacarídeos foliares (CRUZ, 2001). Como a deficiência de nitrogênio reduz o crescimento, a utilização de assimilados pela planta é reduzida e maiores quantidades de carbono podem ser desviadas para a formação de amido (RUfTy Jr. et al., 1988). Se o acúmulo de amido no cloroplasto for excessivo, a fotossíntese pode ser seriamente afetada, por dificultar a chegada do $\mathrm{CO}_{2}$ aos sítios de carboxilação da RubisCO (Guidi et al., 1998).

O efeito da deficiência do nitrogênio sobre o acúmulo dos açúcares solúveis tem gerado alguns resultados divergentes, dependendo da espécie sob estudo. Em tomate, verificou-se acúmulo de sacarose (Guidi et al., 1998), enquanto WANG e Tillberg (1996) observaram aumentos nos níveis de glicose e frutose, mas não nos de sacarose. Entretanto, em girassol, a concentração de nenhum dos três carboidratos citados foi alterada, mesmo após um período de 24 dias de crescimento em solução deficiente de nitrogênio (CIOMPI et al., 1996). Vale ressaltar que o acúmulo de glicose e frutose (CRUZ, 2001) e sacarose (SHEEN, 1990) tem sido relacionado à redução na atividade fotossintética de plantas cultivadas sob deficiência de nitrogênio, em vista da inibição de algumas enzimas do ciclo de Calvin. Essa inibição, que ocorre em nível de repressão do código genético, teria por objetivo ajustar a assimilação de $\mathrm{CO}_{2}$ em função da demanda por carboidratos pelos diferentes drenos da planta em condição de deficiência de nitrogênio (JANG e SHEEN, 1994).

Apesar da constatação que a cultura do mamoeiro absorve considerável quantidade de nitrogênio (Souza et al., 2000) e da importância da nutrição nitrogenada para o crescimento das plantas, pouquíssimos trabalhos têm sido desenvolvidos com essa cultura, visando identificar as alterações relacionadas à partição/alocação de assimilados, decorrentes da deficiência desse nutriente mineral.

$\mathrm{O}$ objetivo do presente trabalho foi o de avaliar o efeito da nutrição nitrogenada sobre a produção e a partição de massa seca e na concentração de açúcares foliares em plantas de mamoeiro. Esses estudos são importantes, à medida que podem servir como subsídios aos trabalhos de melhoramento e nutrição de plantas, que visem identificar e, ou criar genótipos mais eficientes no uso de nitrogênio.

\section{MATERIAL E MÉTODOS}

O presente trabalho foi desenvolvido em casa de vegetação da Embrapa Mandioca e Fruticultura, localizada em Cruz das Almas, Bahia. O município está situado na região do Recôncavo Baiano a $12^{\circ} 40^{\prime} 39^{\prime \prime} \mathrm{S}$ e $39^{\circ} 06^{\prime} 23^{\prime \prime} \mathrm{W}$ e altitude de $220 \mathrm{~m}$. Durante o período experimental a temperatura no interior da casa de vegetação variou de $25^{\circ} \mathrm{C}$ a $29^{\circ} \mathrm{C}$, a umidade de $60 \%$ a $75 \%$ e a luminosidade foi reduzida em $50 \%$. Para esse estudo, usou-se a variedade 'Sunrise solo'. As sementes foram selecionadas, classificadas e colocadas para germinar em vasos plásticos pretos com capacidade para $2,2 \mathrm{dm}^{3}$. O substrato utilizado para o plantio foi composto de uma mistura de vermiculita expandida e turfa processada, lavado várias vezes com água de torneira, visando à retirada de todos os nutrientes que se encontrassem disponíveis. Inicialmente, foram plantadas cinco sementes em cada vaso. Nos primeiros quinze dias, as plantas foram irrigadas duas vezes ao dia, apenas com água de torneira. Após esse período, foram descartadas as plântulas menos vigorosas e o experimento passou a ser desenvolvido com uma planta por vaso. 
Essas plantas passaram, então, a ser fertilizadas com diferentes soluções nutritivas, preparadas para apresentar três concentrações de $\mathrm{NO}_{3}^{-}\left(1,0 ; 3,0 ;\right.$ e 5,0 mol.m$\left.{ }^{-3}\right)$. A concentração final de todos os macros e micronutrientes na solução nutritiva encontra-se descrita na Tabela 1.

Para evitar a salinização, o substrato foi lavado com bastante água de torneira a cada quinze dias e substituídas as soluções nutritivas. $\mathrm{Na}$ substituição, cada vaso recebia $400 \mathrm{~mL}$ das respectivas soluções nutritivas, cujo $\mathrm{pH}$ inicial era sempre ajustado para um valor entre 6,0 e 6,2. Para repor a água perdida por evapotranspiração, realizavam-se irrigações diárias.

Um dia antes do fim do experimento foram tomados dois discos (totalizando 0,0115 $\mathrm{dm}^{2}$ ), da lâmina da última folha completamente expandida para determinar a concentração de clorofilas. Os discos foram imersos em $5 \mathrm{~mL}$ de dimetilsulfóxido (DMSO) e incubados a $70{ }^{\circ} \mathrm{C}$ por 30 minutos, no escuro (Hiscox e Israelstam, 1979). O sobrenadante foi recolhido e a operação repetida mais uma vez. A concentração de clorofila no extrato final foi calculada pela equação de BARNES et al. (1992).

Tabela 1: Concentração final dos macronutrientes das soluções nutritivas de crescimento*

\begin{tabular}{lcccccc}
\hline Tratamentos & $\mathrm{N}^{-N^{-}}{ }_{3}$ & $\mathrm{P}$ & $\mathrm{K}$ & $\mathrm{Ca}$ & $\mathrm{Mg}$ & $\mathrm{S}$ \\
\cline { 2 - 6 } 1 & 1 & 1 & 4 & 2,4 & 1 & \\
\cline { 2 - 7 } & 3 & 1 & 4 & 2,4 & 1 & 3,4 \\
3 & 5 & 1 & 4 & 2,4 & 1 & 2,4 \\
\hline
\end{tabular}

$\left(^{*}\right)$ A concentração dos micronutrientes $\left(\mathrm{mol} \cdot \mathrm{m}^{-3}\right)$ foi: Boro $=0,023$; Cloro $=0,0009$; Manganês = 0,0046; Zinco = 0,0004; Cobre $=0,00002$; Molibdênio $=0,0003$ e Ferro $=0,005$.

No dia em que se encerrou o experimento, aos 64 dias após a semeadura, foram computados, inicialmente, o número de folhas e o comprimento da nervura do lóbulo central de cada folha. Após essas medições, as plantas foram retiradas do substrato, separadas em diferentes partes (folha, caule, pecíolo e raízes), e colocadas para secar em estufa de circulação de ar forçada a $75^{\circ} \mathrm{C}$, por um período de 96 horas. Posteriormente, foram computados os dados de massa seca das folhas, do pecíolo, do caule e das raízes. A área foliar foi estimada pela equação recomendada por Alves e Santos (2002): $\mathrm{AF}=0,085 \mathrm{C}^{2,7835}$, sendo AF a área foliar e $\mathrm{C}$, o comprimento da nervura do lóbulo central de cada folha. Com os dados de massa seca estimaram-se a relação raiz:parte aérea (massa seca da raiz/massa seca da parte aérea), razão de área foliar $(\mathrm{RAF}=$ área foliar $/$ massa seca total $)$, razão de massa foliar (RMF = massa seca das folhas / massa seca total); razão de massa do caule (RMC = massa seca do caule $/$ massa seca total). Após secagem e determinação da massa seca das folhas dos tratamentos 1 e 5 mol.m ${ }^{-3}$, essas foram moídas em moinho tipo WILLY equipado com peneira de 20 mesh, armazenadas e utilizadas para as determinações químicas e bioquímicas. Para determinar o nitrogênio total foram utilizadas as folhas dos três tratamentos.

O teor de nitrogênio total foi determinado pelo método semimicro Kjeldahl, conforme LiaO (1981) e a destilação e titulação segundo BREMNER e EDWARDS (1965). Para determinar o Pi (fósforo inorgânico solúvel em ácido), $500 \mathrm{mg}$ do material foliar seco foi imerso em $10 \mathrm{~mL}$ de $\mathrm{HClO}_{4}$ 0,2 $\mathrm{mol} \mathrm{m}^{-3}$, em mesa de agitação constante por 60 minutos. $\mathrm{O}$ volume do sobrenadante foi ajustado para $25 \mathrm{~mL}$, filtrado e utilizado para a determinação colorimétrica do fósforo a partir da formação da cor azul do complexo fosfatomolibidato, na presença de ácido ascórbico como redutor (EMBRAPA, 1979). A extração dos carboidratos foi realizada por duas vezes com água destilada a $50{ }^{\circ} \mathrm{C}$, sob agitação constante, por 60 minutos e centrifugados a $1.000 \times \mathrm{g}$ por 10 minutos. Posteriormente, os sobrenadantes foram combinados, ajustados para $25 \mathrm{~mL}$, filtrados e armazenados a -20 ${ }^{\circ} \mathrm{C}$ até análise. 
A concentração de açúcares solúveis totais foi determinada pelo método da antrona (HoRwiTz, 1975) e a de açúcares redutores pelo método do ácido dinitrosalisílico (MilLER, 1959), utilizando glicose como padrão. Determinou-se a concentração de açúcares não-redutores pela diferença entre os açúcares solúveis totais e os açúcares redutores. Para análise de amido, tomou-se $500 \mathrm{mg}$ de massa seca e extraiuse três vezes com etanol $80 \%$ a quente, sob agitação constante, seguida de centrifugações a 1.000 × g. Após a última extração, os sobrenadantes foram descartados e os precipitados ressuspendidos por três vezes com ácido perclórico $30 \%$, por 30 minutos, sob agitação constante, e centrifugados a $1.000 \mathrm{x} g$ por 10 minutos. Os sobrenadantes obtidos foram combinados, ajustados para $50 \mathrm{~mL}$ e filtrados. A concentração final de ácido perclórico na solução foi de $6,9 \%$. A determinação do amido foi realizada com base na reação de antrona (HoRwiTz, 1975), utilizando-se glicose como padrão.

O trabalho foi realizado em delineamento experimental de blocos casualizados com três tratamentos (níveis de $\mathrm{N}^{-\mathrm{NO}_{3}^{-}}$) e cinco repetições, sendo cada planta considerada uma parcela experimental. Os dados foram analisados utilizando-se o programa computacional SISVAR - Sistema de Análise de Variância para Dados Balanceados desenvolvido por Ferreira (2000). Para efeito de comparação calculou-se, para cada média, o respectivo erro-padrão da média.

\section{RESULTADOS E DISCUSSÃO}

O menor valor de massa seca total (MST) foi obtido quando as plantas foram cultivadas no substrato irrigado com 1 mol.m ${ }^{-3}$ de $\mathrm{NO}_{3}^{-}$; a partir desse valor, observaram-se aumentos na produção de massa seca, sem, contudo, ter sido verificada diferenças entre as concentrações de 3 e $5 \mathrm{~mol} . \mathrm{m}^{-3}$ (Figura 1A). Entretanto, como houve tendência de maiores produções de matéria seca total em condição do nível mais elevado de $\mathrm{NO}_{3}^{-}$aplicado, a discussão dos resultados será realizada com base nos valores obtidos pelas concentrações de $1 \mathrm{~mol} . \mathrm{m}^{-3}$ (que induziu condição de deficiência) e $5 \mathrm{~mol} \cdot \mathrm{m}^{-3}$ (considerado como o melhor suprimento de nitrogênio).

A produção de MST obtida pelas plantas cultivadas com 5 mol. $\mathrm{m}^{-3}$ foi de $7,75 \mathrm{~g}$, enquanto para a menor concentração de $\mathrm{NO}_{3}^{-} \mathrm{o}$ valor foi de apenas $3,95 \mathrm{~g}$, contabilizando-se uma redução de $49 \%$. A menor produção de MST das plantas foi conseqüência do menor crescimento tanto da parte aérea quanto do sistema radicular.
Para as raízes, os resultados mostraram que a produção de massa seca foi de 1,91 g e 1,05 g, respectivamente, para as plantas cultivadas na maior e na menor concentração de $\mathrm{NO}_{3}^{-}$, com redução de $44 \%$ (Figura 1B).

Em relação à parte aérea, todos os componentes foram afetados em sua massa seca, sendo o pecíolo, com $68 \%$, o mais afetado, seguido da folha e do caule com reduções de $58 \%$ e $38 \%$, respectivamente (Figuras 1C, 1D e 1E). Torna-se importante relatar que a massa seca do caule (MSC) foi a única característica avaliada em que a fertilização nitrogenada de $1 \mathrm{~mol} . \mathrm{m}^{-3}$ apresentou valores semelhantes ao da concentração de $3 \mathrm{~mol} . \mathrm{m}^{-3}$.

O menor valor da produção de massa seca das folhas (MSF) esteve associado ao menor número de folhas (Figura 2A), bem como à redução no tamanho médio das folhas, como pode ser deduzido da menor área foliar [(AF); Figura 2B].

Para o número de folhas a redução observada foi de apenas $15 \%$, enquanto para a área foliar a redução foi cerca $67 \%$, indicando que a deficiência de nitrogênio foi mais prejudicial à expansão das folhas formadas do que a taxa de formação de novas folhas.

A menor expansão das folhas das plantas cultivadas sob condições de deficiência de nitrogênio tem sido associada à redução no potencial de turgescência necessário ao crescimento (RADIN e BOYER, 1982), bem como a redução da extensibilidade plástica da parede celular (PALmer et al., 1996).

A deficiência de nitrogênio afetou negativamente a Razão de Área Foliar [(RAF); Figura 3A], uma característica morfológica e, comparativamente, pode representar a dimensão relativa do órgão assimilador (Magalhães, 1979). A Razão de Massa Foliar [(RMF); Figura 3B], que avalia a capacidade das plantas em direcionar o assimilado produzido para a formação de novos órgãos assimiladores, também foi reduzida pela deficiência de nitrogênio. A RAF foi reduzida em $35,11 \%$, e a $R M F$, em apenas $17,33 \%$.

A maior redução na RAF foi conseqüência da elevada redução observada na AF e reforça a afirmação que a taxa de expansão das folhas é um dos principais mecanismos por meio do qual a deficiência de nitrogênio afeta o crescimento das plantas (CRUZ, 2001). Reduções em RMF e RAF evidenciam que plantas crescidas sob deficiência de nitrogênio aumentaram a proporção entre os tecidos respiratórios e os tecidos fotossintetizantes, como também sugerido por HunT (1990); esse fato pode explicar, ao menos parcialmente, a redução observada nas características de crescimento avaliadas. 

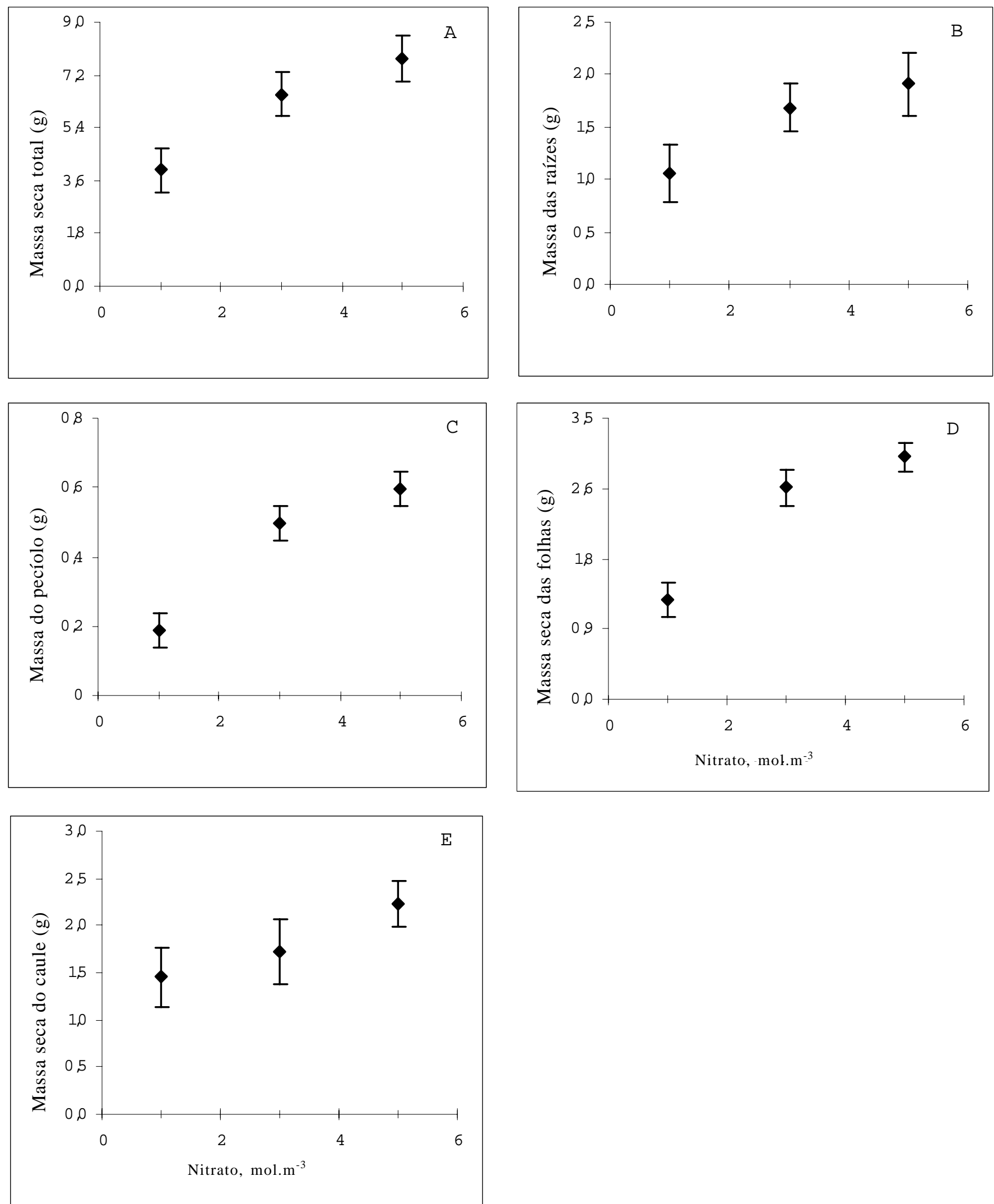

Figura 1. Massa seca total (A), da raiz (B), do pecíolo (C), da folha (D) e do caule (E) de plantas de mamoeiro cultivadas por 64 dias em solução nutritiva com diferentes concentrações de nitrato. Barras representam o erro-padrão da média. 

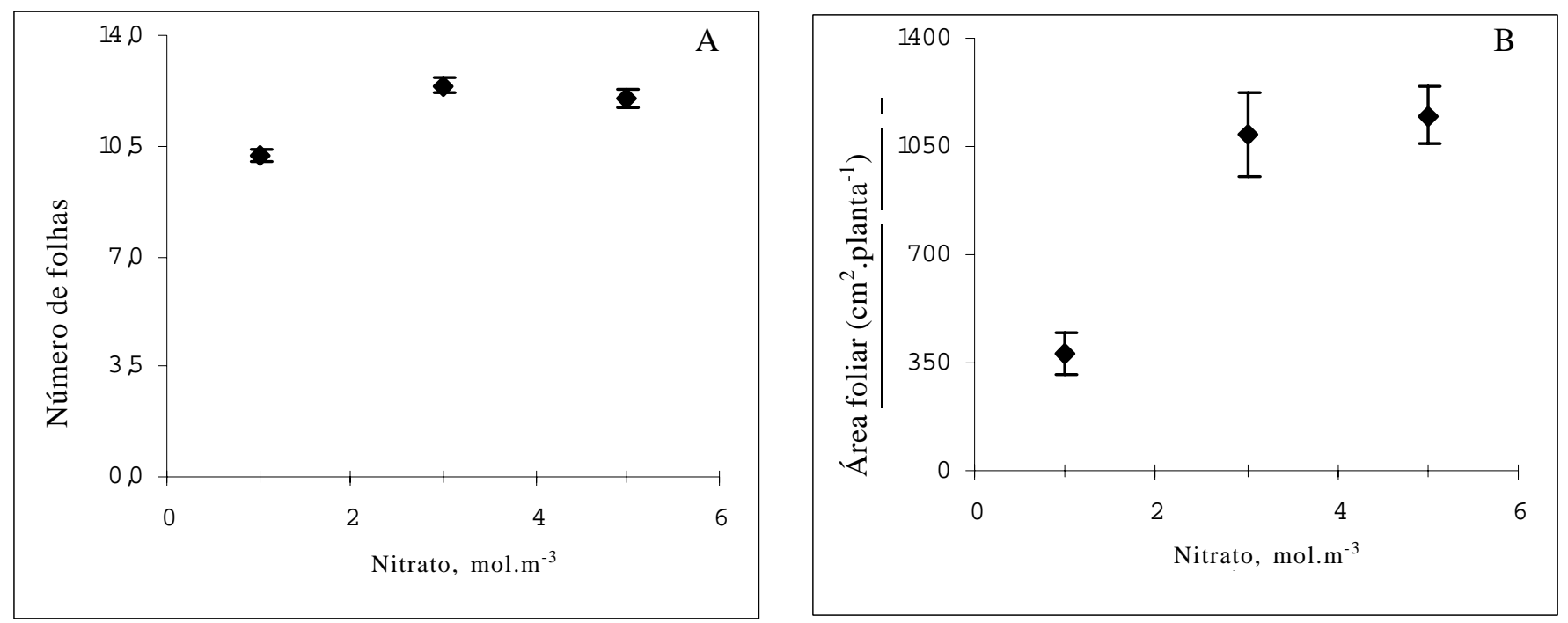

Figura 2. Número de folhas (A) e área foliar (B) de plantas de mamoeiro cultivadas por 64 dias em solução nutritiva com diferentes concentrações de nitrato. Barras representam o erro-padrão da média.

Apesar da redução em MSF ter sido maior do que a redução na massa seca das raízes (MSR) verificou-se que a relação raiz:parte aérea não foi alterada em função da deficiência de nitrogênio (Figura 3C). Assim, os incrementos na MSR e na massa seca da parte aérea, por unidade de massa total, foram os mesmos, independente da fertilização nitrogenada, mostrando não ter havido ajustamento na particão de fotoassimilados entre esses órgãos da planta do mamoeiro. Mesmo quando se considera apenas as radicelas (excetuando-se a raiz principal), não se observaram diferenças na relação raiz:parte aérea (dados não apresentados).

A avaliação da Razão de Massa do Caule [(RMC, Figura 3D] evidencia que o maior valor dessa característica foi obtido pelas plantas cultivadas sob deficiência de nitrogênio, e ajuda a explicar a ausência de alteração na relação raiz:parte aérea entre os tratamentos. Segundo Thornley (1972), plantas eficientes, quando cultivadas sob condições de estresse de nitrogênio, tendem a aumentar a distribuição de matéria seca em direção às raízes ou às folhas, visando minimizar reduções na absorção de nutrientes e de $\mathrm{CO}_{2}$, e favorecer as taxas de crescimento da planta.

Contrariamente, a variedade 'Sunrise solo', utilizada no presente trabalho, distribuiu maiores quantidades de fotoassimilados para o caule, demostrando ajuste inadequado para crescer em ambientes onde a deficiência de nitrogênio seja um problema a ser contornado. A área foliar específica
(AFE), que é um indicativo da espessura da folha e estima a proporção relativa da superfície assimilatória e os tecidos de sustentação e condutores da folha (MAGALHÃES, 1979), foi reduzida em 19,9\% pela menor disponibilidade de nitrogênio (Figura 3E), podendo-se concluir que folhas do mamoeiro, quando crescidas sob deficiência de nitrogênio, tornam-se mais espessas.

A concentração de nitrogênio foliar foi menor nas folhas das plantas cultivadas sob deficiência de $\mathrm{NO}_{3}^{-}$, sem contudo ter existido, à semelhança da massa seca total, diferenças significativas entre os valores obtidos pelas doses 3 e 5 mol. $\mathrm{m}^{-3}$ (Figura 3F). Foram observadas concentrações de nitrogênio de $20,5 \mathrm{mg} \cdot \mathrm{gMS}^{-1}$ para as plantas cultivadas com $1 \mathrm{~mol} \cdot \mathrm{m}^{-3}$ e de 31,46 mg.gMS ${ }^{-1}$ para as cultivadas com 5 mol.m ${ }^{-3}$.

As plantas cultivadas sob menor disponibilidade de $\mathrm{NO}_{3}^{-}$também apresentaram menores concentrações de clorofila total (Figura 4A) e de fósforo inorgânico [(Pi), Figura 4B], com reduções de $45 \%$ e de $62 \%$ respectivamente. Diversos trabalhos têm identificado uma relação positiva e significativa entre a concentração foliar de nitrogênio e a taxa fotossintética líquida (FS), independentemente se a base de expressão é a área ou a massa seca (Evans, 1989), visto que esse elemento é parte integrante dos principais componentes do sistema fotossintético, tais como, clorofila e carboxilase/oxigenase da ribulose 1,5 bisfosfato (RubisCO). Além disso, sob deficiência de nitrogênio, a atividade carboxilativa da RubisCO é seriamente reduzida (CRUZ, 2001). 

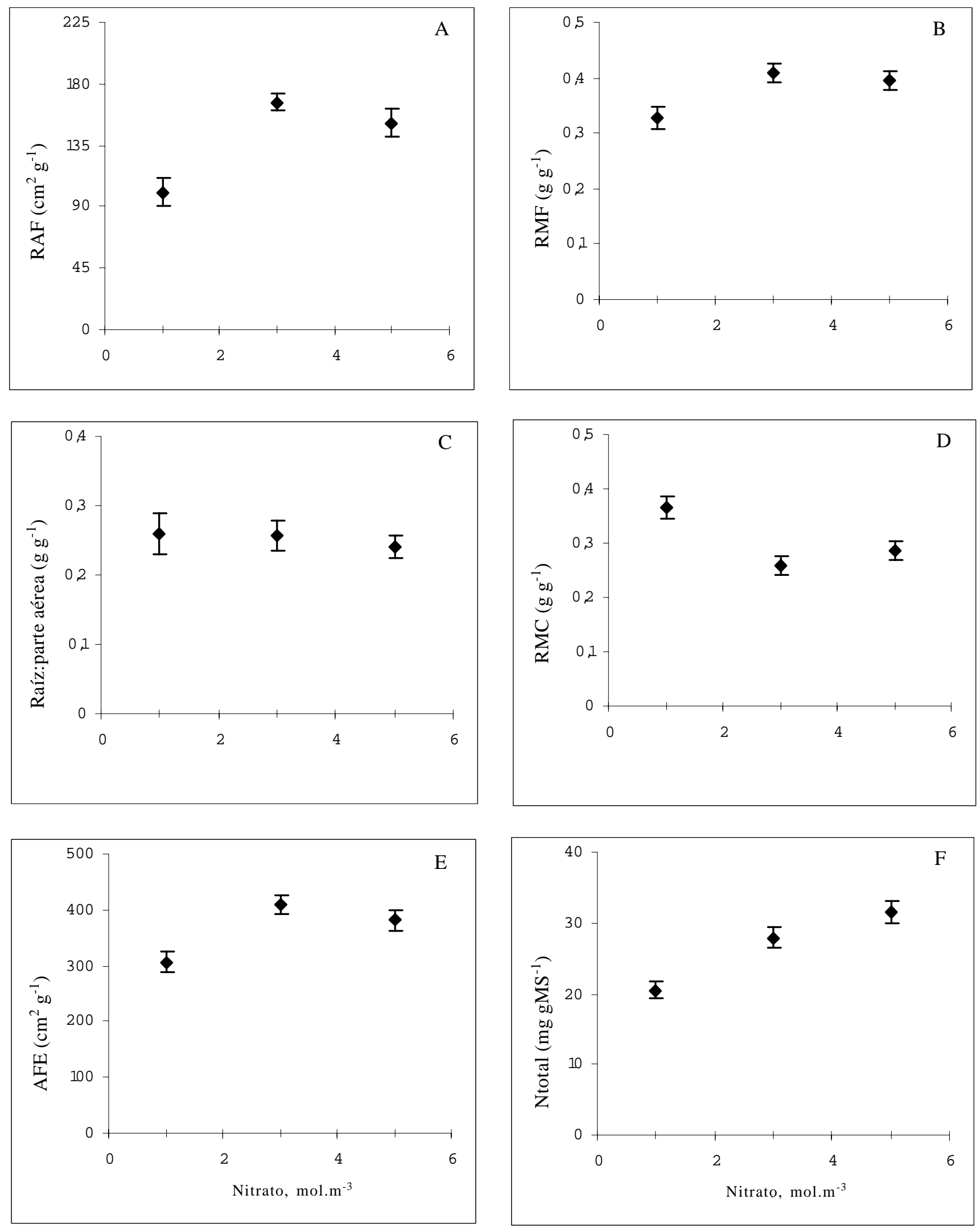

Figura 3. Razão de área foliar (A), razão da massa foliar (B), relação raiz:parte aérea (C), razão da massa do caule (D), área foliar específica (E) e nitrogênio total (F) de plantas de mamoeiro cultivadas por 64 dias em solução nutritiva com diferentes concentrações de nitrato. Barras representam o erro-padrão da média. 
Em adição, menores concentrações de $\mathrm{Pi}$ determinam reduções na quantidade, eficiência de carboxilação e o estado de ativação da RubisCO (LAUER et al., 1989). Assim, é plausível sugerir que plantas de mamoeiro quando cultivadas sob a menor disponibilidade de $\mathrm{NO}_{3}^{-}$, além de apresentar menores concentrações foliares de nitrogênio, Pi e de clorofila, também podem apresentar, como conseqüência, menor taxa de assimilação de $\mathrm{CO}_{2}$; esse pode ter sido um dos fatores que contribuíram para o menor crescimento dessas plantas.

A fertilização nitrogenada influenciou a partição química entre as diferentes frações de açúcares no mesofilo foliar (Figuras 4 e 5). Observouse que a deficiência de nitrogênio reduziu a concentração dos açúcares solúveis totais (Figura 4C) e dos açúcares não-redutores (formado em sua grande maioria por sacarose, Figura 4D) nas folhas de mamoeiro, enquanto não apresentou efeito sobre a concentração de açúcares redutores, compostos,
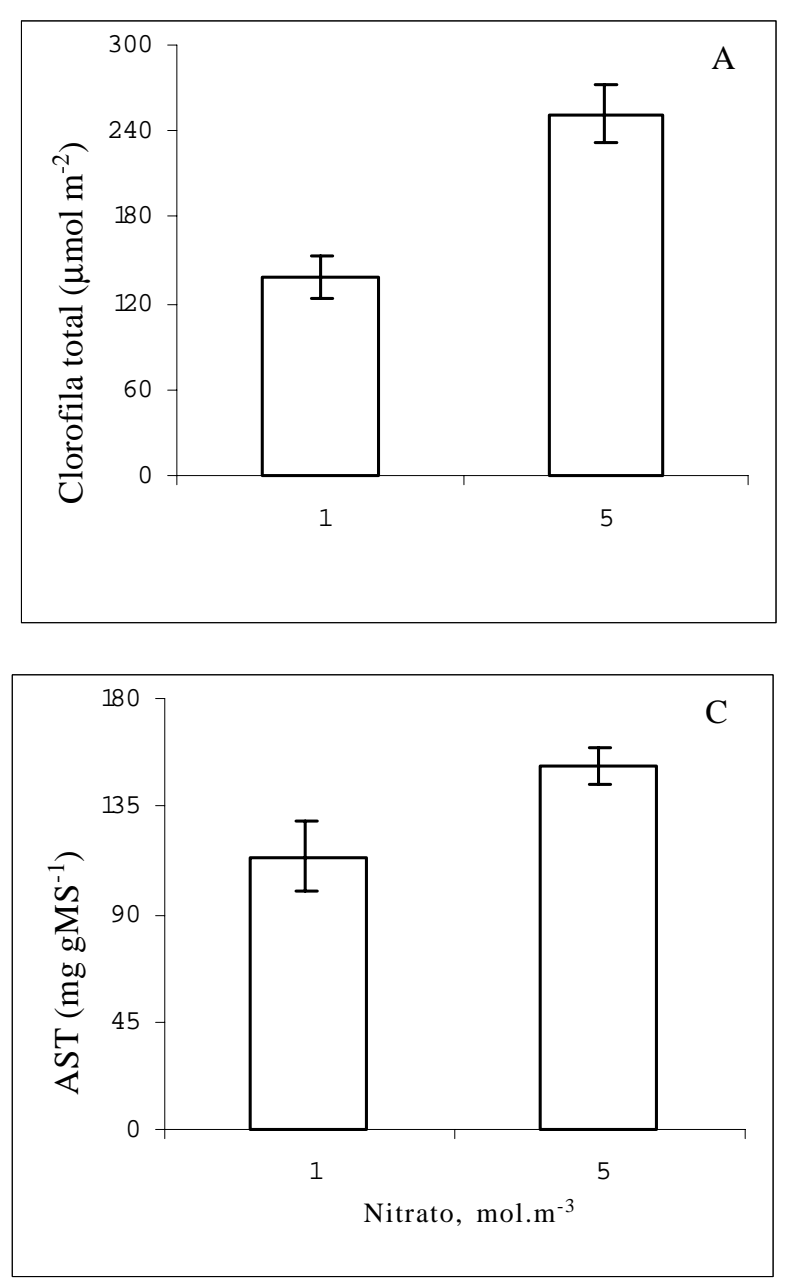

basicamente, de glicose e frutose (Figura 5A). Assim, diferentemente do que tem sido observado por vários autores (Foyer, 1988; WANG e TillberG, 1996; JANG e SHEEN, 1994) a deficiência de nitrogênio não promoveu acúmulo de nenhum dos três principais açúcares solúveis - glicose, frutose e sacarose.

Em relação ao amido, verificou-se que a deficiência de nitrogênio aumentou a concentração desse carboidrato de reserva em 100\% (Figura 5B). Segundo CRUz (2001), uma possível explicação para esse resultado é que a deficiência de nitrogênio reduz o crescimento em maior intensidade do que reduz a taxa fotossintética; dessa maneira, o carbono assimilado e não exportado é direcionado para a formação de amido. A menor formação de aminoácidos e proteínas (como deduzida da menor concentração de nitrogênio foliar das plantas cultivadas com $1 \mathrm{~mol} . \mathrm{m}^{-3}$ ) também pode ter contribuído para o acúmulo de amido das plantas cultivadas sob deficiência de $\mathrm{NO}_{3}^{-}$.
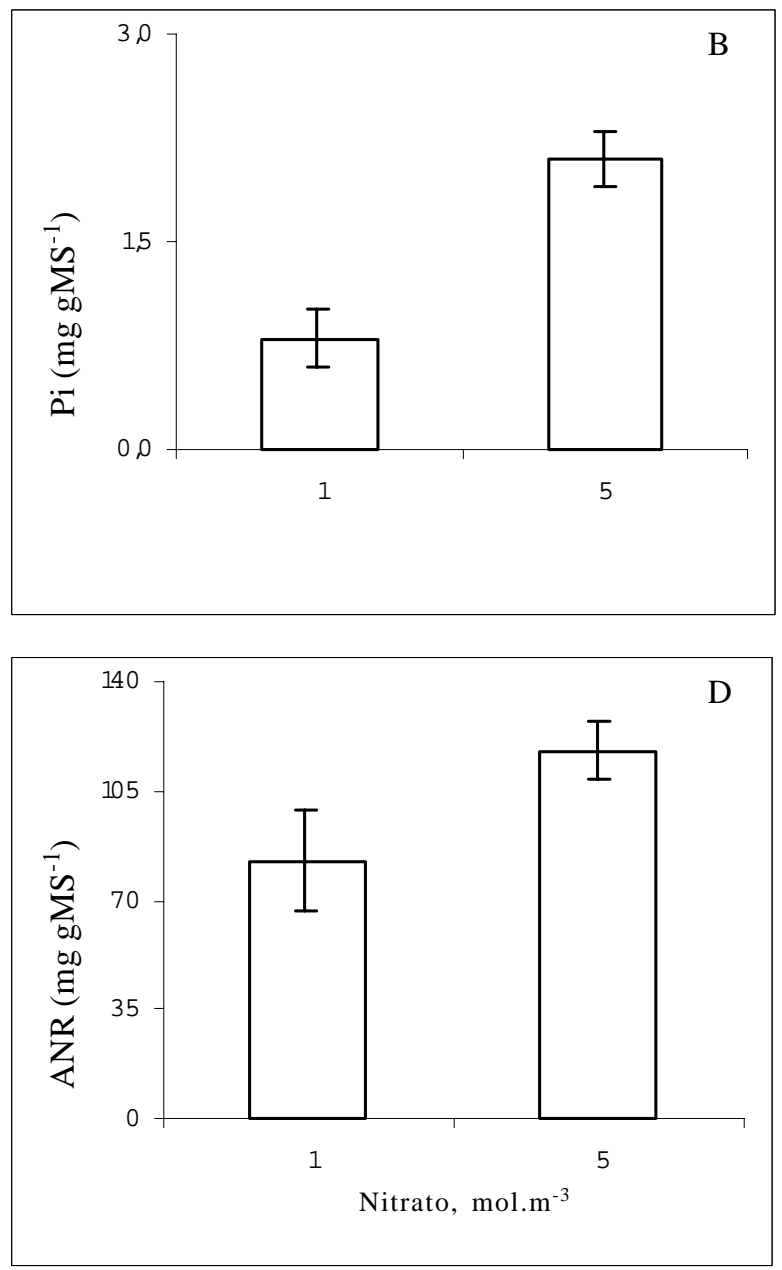

Figura 4. Concentrações de clorofila total (A), fósforo inorgânico (B), açúcares solúveis totais (C) e acúcares não-redutores (D) nas folhas de mamoeiro cultivado por 64 dias em solução nutritiva com diferentes concentrações de nitrato. Barras representam o erro-padrão da média. 
Nota-se que plantas cultivadas sob altos níveis de nitrogênio tendem a reduzir o fluxo de carbono em direção à formação de amido e promover aumentos na síntese de ácidos orgânicos que podem ser utilizados como esqueletos de carbono para a formação de aminoácidos (SCHeible et al., 1997). Ao contrário, quando a deficiência de nitrogênio é induzida, ocorre redução na demanda por fotoassimilados para a formação de aminoácidos e proteínas e, conseqüentemente, aumento na disponibilidade de hexoses que podem ser utilizadas para a produção de amido (RoBINSON, 1996). Adicionalmente, a redução na concentração de Pi citossólico (Figura 4B), que dificulta a saída da triose fosfato dos cloroplastos, também pode ter contribuído para a formação de amido das plantas cultivadas sob deficiência de nitrogênio.

A redução na concentração dos açúcares nãoredutores nas folhas das plantas que receberam 1 mol.m ${ }^{-3}$ de $\mathrm{NO}_{3}^{-}$(Figura 4D) evidencia que a formação de amido ocorreu em detrimento da formação de sacarose, em similaridade ao observado por outros autores (Huber e IsRael, 1982; CRUZ 2001). De fato, tem sido observado que a deficiência de nitrogênio concorre para redução da atividade da sintase da sacarose fosfato, principal enzima da via relacionada à formação da sacarose (KERR et al., 1984; Isopp et al., 2000) enquanto pode estimular a atividade da principal enzima relacionada à formação de amido (StiTt, 1999). Para KerR et al. (1986), o processo que regula a alocação de carbono entre amido e sacarose, é mais dependente da nutrição nitrogenada do que a própria taxa fotossintética.

Na fonte, a maior formação de sacarose, e não de amido, possibilita a manutenção dos potenciais de turgescência do floema em condições fisiológicas, favorecendo a exportação dos compostos formados (Scheible et al., 1997) e o crescimento dos diversos drenos da planta. Assim, a avaliação da razão entre a concentração de amido e a concentração de sacarose pode indicar a existência de alterações na partição de fotoassimilados, entre as diferentes partes da planta (GAltier et al. 1993). Como no presente trabalho, a razão amido/ANR(sacarose) foi maior para as plantas cultivadas sob menor disponibilidade de nitrogênio (Figura 5C), é possível inferir que o nível de exportação dos fotoassimilados produzidos pode ter sido reduzido, o qual ajuda explicar o menor crescimento apresentado por essas plantas.
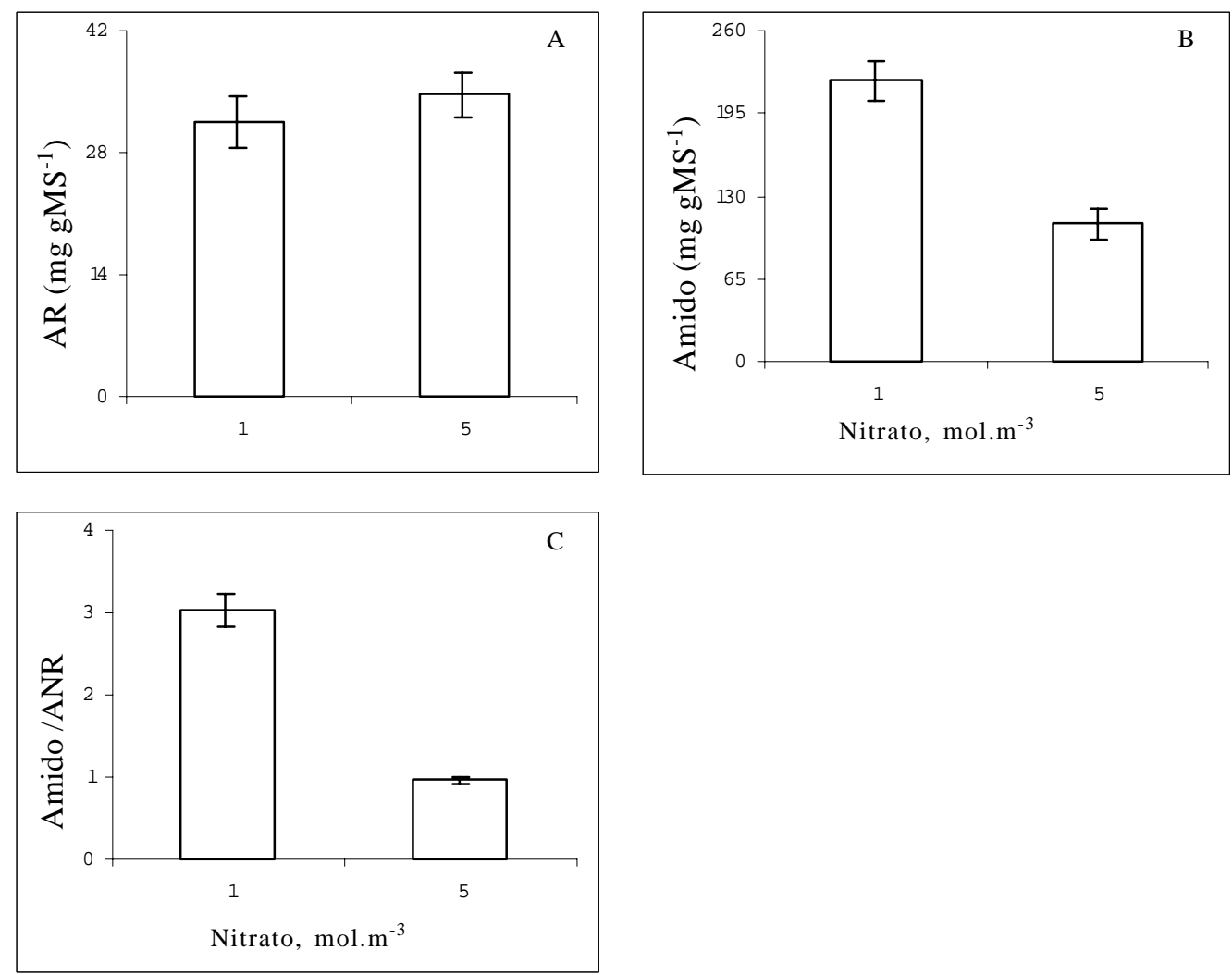

Figura 5. Concentrações de açúcares redutores (A), amido (B) e relação amido/ANR (C) nas folhas de mamoeiro cultivado por 64 dias em solução nutritiva com diferentes concentrações de nitrato. Barras representam o erropadrão da média. 


\section{CONCLUSÕES}

1. Sob deficiência de nitrogênio houve redução no crescimento e alteração na partição de matéria seca. No entanto, não se verificaram mudanças da relação raiz:parte aérea das plantas;

2. A deficiência de nitrogênio reduziu a concentração dos açúcares solúveis totais e açúcares não-redutores e aumentou a concentração de amido foliar. Em função disso, houve aumento da relação amido/ANR dessas plantas, revelando que a deficiência de nitrogênio pode ter contribuído para a redução na exportação dos assimilados produzidos.

\section{REFERÊNCIAS}

ALVES, A.A.C.; SANTOS, E.L. Estimativa da área foliar do mamoeiro: método não destrutivo. In: CONGRESSO BRASILEIRO DE FRUTICULTURA, 22., EMBRAPA: Belém, 2002. (CD Rom)

BARNES, J.D.; BALAGUER, L.; MANRIQUE, E.; ELVIRA, S.; DAVISON, A.W. A reappraisal of the use of DMSO for the extraction and determination of chlorophylls $a$ and $b$ in lichens and higher plants. Environmental and Experimental Botany, Oxford, v.32, p.85-100, 1992.

BREMNER, J.M.; EDWARDS, A.P. Determination and isotope ratio analysis of different form of nitrogen soil. I. Apparatus and procedures for distillation and determination for ammonium. Soil Science Society of American Proceedings, Madison, v.29, p.504-507, 1965.

CIOMPI, S.; GENTILI, E.; GUIDI, L.; SOLDATINI, G. F. The effect of nitrogen deficiency on leaf gas exchange and chlorophyll fluorescence parameters in sunflower. Plant Science, Limerik, v. 118, p.177-184, 1996.

CRUZ, J.L. Efeitos de níveis de nitrato sobre o metabolismo do nitrogênio, assimilação do $\mathrm{CO}_{2}$ e fluorescência da clorofila $a$ em mandioca. 2001. 87f. (Tese de doutorado) - Universidade Federal de Viçosa, Viçosa.

EMPRESA BRASILEIRA DE PESQUISA AGROPECUÁRIA. Serviço Nacional de Levantamento e Conservação de Solos. Manual de métodos de análise do solo: Rio de Janeiro, 1979. Não paginada.

EVANS, J.R. Photosynthesis and nitrogen relationship in leaves of $\mathrm{C}_{3}$ plants. Oecologia, Berlim, v. 78, p.9-19, 1989.

FAO. Site FAO (2002). Disponível em: http://apps.fao.org/ page/collections?subset=agriculture . Consultado em 13 de agosto de 2003.

FERREIRA, D.F. Análises estatísticas por meio do Sisvar para Windows versão 4.0. In: REUNIÃO ANUAL DA REGIÃO BRASILEIRA DA SOCIEDADE INTERNACIONAL DE BIOMETRIA, 45., 2000, São Carlos. Anais... São Carlos:UFSCar, 2000. p.255-258.
FOYER, C.H. Feedback inhibition of photosynthesis through source-sink regulation in leaves. Plant Physiology and Biochemistry, Paris, v. 26, p. 483-492, 1988.

GALTIER, N.; FOYER, C.H.; HUBER, J.; VOELKER, T.A.; HUBER, S.C. Effects of elevated sucrose phosphate synthase activity on photosynthesis, assimilate partitioning and growth in tomato (Licopersicum esculentum var. UC82B). Plant Physiology, Bethesda, v.101, p.535-543, 1993.

GREENWOOD, D.J.; GASTAL, F.; LEMAIRE, G.; DRAYCOTT, A.; MILLARD, P.; NEETESON, J.J. Growth rate and \% N of field grown crops: theory and experiments. Annals of Botany, London, v.67, p.181-190, 1991.

GUIDI, L.; LOREFICE, G.; PARDOSSI, A.; MALORGIO, F.; TOGNONI, F.; SOLDATINI, G.F Growth and photosynthesis of Lycopersicum esculentum (L.) plants as affected by nitrogen deficiency. Biologia Plantarum, Prague, v.40, p.235-244, 1998.

HISCOX, J.D.; ISRAELSTAM, G.F. A method for the extraction of chlorophyll from leaf tissue without maceration. Canadian Journal of Botany, Ottawa, v.57, p.1332-1334, 1979.

HORWITZ, W. Official methods of analysis of the Association of Official Analytical Chemistry. Washington: AOAC, 1975.357p.

HUNT, H. Basic growth analysis. Londres: Unwin Hyman, 1990. 112 p.

HUBER, S.C.; ISRAEL, D.W. Biochemical basis for partitioning of photosynthetically fixed carbon between starch and sucrose in soybean (Glycine max Merr) leaves. Plant Physiology, Bethesda, v.69, p.691-696, 1982.

ISOPP, H.; FREHNER, M.; LONG, S.P.; NÕSBERGER, J. Sucrosephosphate synthase respond differently to source-sink relation and to photosynthetic rates: Lolium perene L. growing at elevated pCO2 in the field. Plant Cell Environment, Oxford, v.23, p.597-607, 2000.

JANG, J.C.; SHEEN, J. Sugar sensing in higher plants. Plant Cell, Rockville, v.6, p.1665-1679, 1994.

KERR, P.S.; ISRAEL, D.W.; HUBER, S.C.; RUFTY, Jr. T.W. Effects of supplemental $\mathrm{NO}_{3}^{-}$on plant growth and components of photosynthetic carbon metabolism in soybean (Glycine Max). Canadian Journal of Botany, Ottawa, v. 64, p. 2020-2027, 1986.

LAUER, M.J.; PALLARDY, S.G.; BLEVINS, D.G.; RANDALL, D.D. Whole leaf carbon exchange characteristic of phosphate deficient soybean (Glycine Max L.). Plant Physiology, Bethesda, v.91, p.848-854, 1989.

LIAO, C.F.H. Devard's alloy method for total nitrogen determination. Soil Science Society of American Journal, Madison, v.45. p.852-855. 1981.

MAGALHÃES, A.C.N. Análise quantitativa do crescimento. In: FERRI, M.G. (Coord.). Fisiologia Vegetal. São Paulo:EPU, 1979. v.1, 362p.

MILLER, G.L. Use of dinitrosalysicylic and reagent for determination of reducing sugar. Analytical Chemistry, Washington, v.31, p.426-428. 1959. 
PALMER, S. J.; BERRIDGE, D.M.; MCDONALD, A.J.S.; DAVIES, W.J. Control of leaf expansion in sunflower (Helianthus annus L.) by nitrogen nutrition. Journal of Experimental Botany, London, v.47, p.359-368, 1996.

RADIN, J.W.; BOYER, J.S. Control of leaf expansion by nitrogen nutrition in sunflower plants. Role of hydraulic conductivity and turgor. Plant Physiology, Bethesda, v.69, p.771-775, 1982.

ROBINSON, J.M. Leaflet photosynthesis rate and carbon metabolite accumulation patterns in nitrogen-limited, vegetative soybean plants. Photosynthesis Research, Hague, v.50, p.133-148, 1996.

RUFTY Jr., T.W.; HUBER, S.C.; VOLK, R.J. Alterations in leaf carbohydrate metabolism in response to nitrogen stress. Plant Physiology, Bethesda, v.88, p.725-730, 1988.

SCHEIBLE, W.R.; GONZALEZ-FONTES, A.; LAUERER, M.; MULLER-ROBER, B.; CABOCHE, M.;STITT, M. Nitrate acts as a signal to induce organic acid metabolism and repress starch metabolism in tobacco. Plant Cell, Rockville, v.9, p.783-798, 1997.
SHEEN, J. Metabolic repression of transcription in higher plants. Plant Cell, Rockville, v.2, p. 1027-1038, 1990.

SOUZA, L.F.S.; TRINDADE, A.V.; OLIVEIRA, A.G. Calagem, exigências nutricionais e adubação. In: TRINDADE, A.V. (Org.). Mamão. Produção: aspectos técnicos. Cruz das Almas: EMBRAPA Mandioca e Fruticultura. Brasília: EMBRAPA Comunicação para transferência de Tecnologia, 2000. 77 p. (Frutas do Brasil, 3).

STITT, M. Nitrate regulation of metabolism and growth. Current Opinion in Plant Biology, London, v.2, p.178-186, 1999.

THORNLEY, J.H.M. A balanced quantitative model for root:shoot ratios in vegetative plants. Annals of Botany, London, v. 36, p. 431-441, 1972.

WANG, C.W.; TILLBERG, J.-E. Effects of nitrogen deficiency on accumulation of fructan and fructan metabolizing enzymes activities in sink and source leaves of barley (Hordeum vulgare). Physiologia Plantarum, Copenhague, v.97, p.339-345, 1996. 